\title{
Interparticle Movement and the Mechanical Behavior of Extruded Powder Aluminum at Elevated Temperature
}

by

H. B. Peacock

Westinghouse Savannah River Company

Savannah River Site

Aiken, South Carolina 29808

A document prepared for EXPERIMENTAL TECHNIQUES SOCIETY OF EXPERIMENTAL MECHANICS, INC. at Orlando from 01/30/97 - 02/01/97.

\section{DOE Contract NO. DE-AC09-89SR18035}

This paper was prepared in connection with work done under the above contract number with the U.S. Department of Energy. By acceptance of this paper; the publisher and/or recipient acknowledges the U.S. Government's right to retain a nonexclusive, royalty-free license in and to any copyright covering this paper, along with the right to reproduce and to authorize others to reproduce all or part of the copyrighted paper. 


\section{DISCLAIMER}

This report was prepared as an account of work sponsored by an agency of the United States Government. Neither the United States Government nor any agency thereof, nor any of their employees, makes any warranty, express or implied, or assumes any legal liability or responsibility for the accuracy, completeness, or usefulness of any information, apparatus, product, or process disclosed, or represents that its use would not infringe privately owned rights. Reference herein to any specific commercial product, process, or service by trade name, trademark, manufacturer, or otherwise does not necessarily constitute or imply its endorsement, recommendation, or favoring by the United States Government or any agency thereof. The views and opinions of authors expressed herein do not necessarily state or reflect those of the United States Government or any agency thereof.

This report has been reproduced directly from the best available copy.

Available to DOE and DOE contractors from the Office of Scientific and Technical Information, P.O. Box 62, Oak Ridge, TN 37831; prices available from (615) 576-8401.

Available to the public from the National Technical Information Service, U.S. Department of Commerce, 5285 Port Royal Road, Springfield, VA 22161. 


\section{DISCLAIMER}

Portions of this document may be illegible in electronic image products. Images are produced from the best available original document. 
Interparticle Movement and the Mechanical Behavior of Extruded Powder Aluminum at Elevated Temperature

by

T.O. Woods, D.G. Berghaus and.H.B. Peacock

Introduction

The basic mechanical behavior of extruded powder aluminum has been observed to differ noticeably from that of ingot-cast ard drawn aluminum when tests are performed at elevated temperature (1). Powder aluminum exhibits a post-yield "strain softening" effect. This effect is evident in a decrease of stress with increasing strain in uniaxial test specimens when the experiment proceeds into the post yield region.

Similar behavior is observed when the material is loaded biaxially where the application of tensile loading together with torsion produces a comparable effect in the torsional shear response. In this case there is a strain softening in the shear response. In addition, the shear stress is decreased further with increasing axial extension.

This paper proposes a model and mechanism, based on relative motion of the extruded aluminum particles, to explain these effects.

Quantitative stereology is used to support the concept. Stress-strain relations are derived for the uniaxial and biaxial behavior of powder aluminum and they are seen to fit the data from a number of uniaxial and tension-torsion test specimens.

Implications of the model for forming of extruded powder metal products are discussed.

\section{Mechanical Behavior of Extruded Powder Aluminum}

A series of experiments was performed using test specimens made of Alcoa 101 aluminum powder[1]. Uniaxial tensile tests were performed, as well as biaxial tension-torsion tests, using a computer controlled tension-torsion testing machine fitted with a high temperature chamber.

The test program consisted of a matrix of experiments which included combinations of combined tension-torsion loadings extending from uniaxial tension to simple torsion. All tests were performed at a temperature of $400^{\circ} \mathrm{C}$. Experiments were performed using displacement control. Loads were applied simultaneously to produce different maximum axial extension values and different angles of twist. A limited number of specimens was available. For purposes of comparison, the same experiments were performed with alloy $1100-F$, an alloy of aluminum consisting of more than 99 per cent AI. 
Hollow cylindrical test specimens were used with a gage length of $7.6 \mathrm{~cm}$, outside diameter of $1.3 \mathrm{~cm}$ and wall thickness of $2.4 \mathrm{~mm}$. For the torsion tests, it was possible to produce an angle of twist of $95^{\circ}$ over the gage length. Care was taken to identify coordinate directions associated with the testing axes and with the changing material angle due to twist. Calculations also were careful to respect rigorous considerations of strain in a large deformation problem.

Uniaxial test results relevant to this paper are given in Figure 1. Shear results from biaxial tests are given in Figure 2. In both figures, the specimens are included which were loaded to produce strains significantly beyond the point of yield. In these figures, the " $n$ " direction is along the test and specimen axis. It is the tensile loading direction. Angle, theta, rotates about this axis, which is the axis of the applied torsion.

\section{Microscopic structure}

Air atomized aluminum powder was precompacted into billets and then extruded through conical reducing dies to produce cylindrical rods. The extrusion ratio was 15:1. The specimens used in this study were machined from these rods. Certain features apparent in the basic structure of the processed material are important to its mechanical behavior.

Inherent discontinuity of the powder metal is retained in the presence of small void regions throughout the billet. Though reduced in size and changed in geometry, voids are retained through the fabrication procedures. They are generally found in all powder metal: (PM) products.

Surfaces of powder aluminum particles are coated with an aluminum oxide film. During extrusion this film becomes distributed as stringers of oxide, oriented in the extrusion dircotion [2-5]. These stringers prevent complete bonding between the particles, producing a laminar structure which is absent in ingot-cast and drawn aluminum.

Many authors have commented on the deleterious effects of oxides on PM mechanical properties $[6,7]$. The oxide film has been found to influence internal friction, shear modulus and Young's modulus in magnesium alloys and beryllium cermets $[8,9]$. Oxide inclusions may embrittle $P M$ steels, and the oxide $f i l m$ on previous particle boundaries may provide locations for delamination, resulting in inferior toughness properties in PM steels and $P M$ aluminum alloys $[10,11]$. Debonding at prior particle boundaries was also observed in Astroloy [12]. The oxide films have been known to influence material properties, but little attention has been directed towards examining and understanding the mechanisms present during deformation. Several investigators have stated that these mechanisms need to be investigated $[10,13,14]$.

\section{Quantitative stereoloav}

Basic stereological relations can be used to study the microscopic structure. The method used in this analysis is the point count which 
allows the determination of the volume fraction of a constituent from the examination of a photomicrograph of the material. The volume fraction of a constituent is equal to the number of test points in the photomicrograph which lie within the constituent boundaries divided by the total number of test points [15]. In practice, a test grid is printed on a transparency and is placed over a micrograph, and intersections on the grid are used as test points. From a number of random grid placements, a point count may be calculated:

$$
P_{P}=\frac{\Sigma P}{P_{t}}=\frac{\Sigma P}{n P_{P}}
$$

where $\mathrm{p}$ is the number of test points which lie over the feature of interest (constituent), $P_{t}$ is the number of test points, $\Omega$ is the number of grid placements and $p_{0}$ is the number of grid points [16].

\section{Development of Model}

Figure 1 clearly shows two regions of behavior in uniaxially loaded PM specimens. There is a region of increasing stress with strain, followed by the decreasing stress with strain (strain softening).

only the results for specimens tested into the second region are shown. The test program also included several specimens tested to lower maximum strains. Despite a large variation in maximum stress values, the average modulus for all specimens in the initial region, $720 \mathrm{MPa}$, was close to that for the tested 1100 aluminum, $740 \mathrm{MPa}$ [1].

While the maximum stress varies for the PMi specimens, it is uniformly higher than the ultimate stress for the 1100 aluminum. yield behavior is similar for all PM specimens with similar rates of decrease for the stress. The specimens could be loaded to maximum extensional strains of less than 0.15 , at which time they failed in a brittle manner, without noticeable reduction in cross section. The 1100 aluminum experienced ductile behavior with maximum extensional strains greater than 0.4 and large reductions in cross sectional area. calculation corrections for reduced cross section were made for the latter specimens, which then displayed the expected strain hardening.

\section{Uniaxial Tension Material. Deformation Model}

Extruded powder aluminum has a laminar structure which consists of greatly elongated powder particles, as may be seen in Figure 3 . The particles are surrounded by regions containing aluminum oxide. At low levels of tensile load and tensile strain, the oxide provides a rigid supporting structure which strengthens the material, as evidenced by the fact that the powder aluminum supports a higher maximum stress than 1100 aluminum. As loading continues, the oxide contributes to the failure of the material by inhibiting adhesion between the particles. At high 
tensile strains, there is an increase in void content due to growth in the number, length, and width of separations between the laminae or ligaments as shown in Figure $4 \mathrm{a}$. This increase can be quantified using the point count method.

The separations that predominate are the result of relative motion between the extruded and greatly elongated particles of powdèr aluminum. Terminations or ends of the elongated particles also contribute to the inherentiy discontinuous structure (on a microscopic level) of the extruded powder laminae. The particle terminations produce regions of discontinuity where loading is shifted between the laminae. The relative motion produces regions in the material where the net cross section of the aluminum material is decreased as is shown schematically in Figure 4b. Specimen failure eventually occurs at one of these locations of reduced cross sectional area. The decrease in cross sectional area was studied experimentally using the point count method. For instance, point counts showed that a specimen with a final extensional strain of 0.026 contained 1.9 times more void and oxide area than untested material from the same billet, and a specimen which experienced a maximum extensional strain of 0.076 contained 2.4 times more oxide and void area than the untested material.

Results from powder aluminum specimens tested in uniaxial compression also supported this explanation of failure. Point count results showed that compression specimens that experienced less strain contain more void and oxide area than specimens that experienced greater compressive strains. This would indicate that as the specimens were compressed, the aluminum ligaments were squeezed together, decreasing the content of laminar separations in the material.

An examination of the stress-strain curves for the uniaxial tension specimens suggests the following description of post-yield behavior based on the presence of laminae (or ligaments) of aluminum separated by regions containing aluminum oxide: After the material yields, there is an apparent drop in the stress caused by a decrease in the internal cross sectional area of aluminum which arises. When the ligaments slip over each other. There is no decrease in overall cross sectional dimensions of the test specimen. On the contrary, there is an increase in void area which results in a smaller effective area of aluminum which supports the load. In a deformation controlled experiment there is a reduced load. The stress-strain curve for 1100 aluminum in Fig. 1 is used to describe the material behavior of the aluminum ligaments in the powder material. For uniaxial tension, the axis of the load remains aligned with the aluminum ligaments, and for the post-yield region, a linear material strain. hardening coefficient is assumed, such that:

$$
\sigma_{n}=\sigma_{0}\left(1+C_{1} \epsilon_{n}\right)
$$

where

$$
\begin{aligned}
& \sigma_{n}=\text { normal stress in ligaments } \\
& \epsilon_{n}=\text { extensional along specimen axis }
\end{aligned}
$$




$$
\begin{aligned}
& \sigma_{0}=\text { yield stress in } 1100 \text { aluminum } \\
& c_{1}=\text { strain hardening coefficient }
\end{aligned}
$$

For the post yield behavior of the powder material, the load on the specimen is related to the load in the ligaments:

$$
P=\left(\sigma_{n}\right) A
$$

where

$$
\begin{aligned}
\mathrm{p}= & \text { applied load } \\
\mathrm{A}= & \text { cross sectional area of aluminum ligaments in powder aluminum } \\
& \text { specimen }
\end{aligned}
$$

As the ligaments slip over each other, the void volume increases such that the internal cross sectional area in the powder aluminum is assumed to decrease 1 inearly with strain and:

$$
A=A_{I}-k_{2} \epsilon_{n}
$$

where

$$
\begin{aligned}
A_{1}= & \text { initial cross sectional area } \\
k_{2}= & \text { constant relating decreasing internal cross sectional area to } \\
& \epsilon_{n}
\end{aligned}
$$

Substituting equations 2 and 4 into equation 3 gives the load in the powder material which includes the material behavior of the aluminum i igaments (from the 1100 aluminum stress-strain curve and also considers the decrease in area which occurs as the ligaments silp over each other:

$$
P=0_{0} Q_{2}\left[A_{1}+\epsilon_{n}\left(A_{2} c_{1}-k_{2}\right)-c_{2} k_{2} \epsilon_{n}^{2}\right]
$$

where $Q_{1}$ is a constant which represents the supporting effect of the aluminum oxide at lower levels of strain. Both sides of equation 5 may be divided by $A_{I}$ to obtain $\sigma_{n}$, the $P M$ normal stress in the axial direction:

$$
\sigma_{n}=\sigma_{0} Q_{1}\left[1+\left(c_{1}-k_{1}\right) \epsilon_{n}-c_{2} k_{1} \epsilon_{n}^{2}\right]
$$

where

$\sigma_{0}=y$ ield stress in 1100 aluminum

$Q_{1}=$ constant representing supporting effect of aluminum oxide

$c_{1}=$ strain hardening coefficient

$\epsilon_{\mathrm{n}}=$ extensional; strain along specimen axis

$\mathrm{k}_{1}$ =constant representing decreasing internal cross sectional area to $\epsilon_{n}$ normalized with respect to initial cross section $A_{1}$ 
Uniaxial tensile tests were performed to determine the material constants for equation 6 and then to test the fit of the equation over the appropriate span of the data. Figure 5 shows the normal stress vs extensional strain together with the fit from equation 6 for two of the powder aluminum specimens tested in simple tension. The constants are found by performing a least squares fit of the data in the post-yield region to equation 6 . For the specimen in Fig. 5a, $Q_{1}=1.7, c_{1}=5.6$. and $k_{1}=5.4$. For the specimen in Fig. $5 \mathrm{~b}, Q_{i}=2.4, c_{1}=5.0$, and $k_{1}=$ 4.1. The yield stress for 1100 aluminum, determined from the data in figure 1, is $12 \mathrm{MPa}$. The calculated values for $c_{1}$ are close to the average value of 6.7 obtained from the slopes of the stress strain curves from 1100 aluminum tested in simple tension, indicating that the model provides a reasonable explanation for the post-yield behavior of the extruded powder aluminum.

\section{Biaxial (Tension-Torsion) Material Deformation Model}

During simple tension tests beyond the yield point, the axial normal stress produces relative motion between the aluminum Iigaments which causes a reduction of the internal cross sectional area of the specimen. Simultaneously, the axial load and corresponding axial stress decrease with the increasing axial elongation.

Figure 2 shows results for the biaxial tension-torsion tests. Here, the axial normal stress, sigman, is supplemented by a torsional shear stress, $\operatorname{tau}_{n}$, on planes normal to the specimen axis. The experiments produced an initial region where shear stress increases linearly with shear strain up to the yield point. After this point, there is a decrease in shear stress for increasing shear strain.

Figure 6 is an idealized view within the wall of a tension-torsion specimen viewed normal to the surface in the radial direction. Under the torsional loading, the ligaments rotate to make an angle, $\alpha$, with the specimen extrusion axis, the $n$ axis. The skewing is apparent when polished sections of the specimen wall are viewed microscopically. For the tension-torsion tests, stress components are considered using the $n-$ theta coordinate system which is aligned with the specimen axis together with the $x-y$ system which is aligned with the rotated ligaments, as shown in Figure 6 .

Effects of the normal stresses in the $x-y$ system, paraliel and perpendicular to the aluminum ligaments help to explain the deformation behavior. Addition of the torsional stress produces a stress component, $\sigma_{y}$, normal to the ligaments. The value for this stress may be obtained by stress transformation(17):

$$
\sigma_{y}=\sigma_{i 2} \sin ^{2} \alpha+\sigma_{\theta} \cos ^{2} \alpha-2 \tau_{n \theta} \sin \alpha \cos \alpha
$$


It may be seen that a simple shear test, with small $\sigma_{n}$ and high ${ }^{\prime} n \theta^{\prime}$ produces a negative (compressive) value for ${ }^{\circ} y$. Increasing the value of axial stress, $\sigma_{n}$, produced by the axial load, reduces the magnitude of $\sigma_{y}$. (For tension-torsion loading $\sigma_{\theta}=0$. ) A "clamping effect" is produced by $\sigma_{y}$ which acts to squeeze the ligaments together. inhibiting relative motion. Thus, the clamping effect reduces the decrease in cross sectional area and acts to prevent the torque and shear stress from decreasing. But with increasing axial stress (and axial strain, $\epsilon_{n}$ ), the clamping effect diminishes. It is thus apparent that the diminished clamping permits the increased strain softening with axial extension, as seen in Figure 2 .

A post-yield stress-strain relation for shear may be obtained for biaxial loading of the extruded powder aluminum. For 1100 aluminum, linear strain hardening will be used for the post-yield region:

$$
\tau_{r \theta}=\tau_{\text {or }}\left(1+C_{r} \gamma_{n \theta}\right)
$$

where $\tau_{\text {or }}$ and $c_{r}$ are yield stress and strain hardening coefficient values for shear for 1100 aluminum experiencing strain ratio, $(\epsilon / \gamma), r$.

The torque transmitted by the specimen is equal to the product of the shear stress in the ligaments, the total cross-sectional area of the ligaments and their radii to the specimen axis. The ligament shear stress is given by equation 7 and is presumed to be constant over the effective total ligament cross sectional area. Thus for the torque:

$$
T=\tau(A)\left(r_{R i}\right)=\varnothing \tau_{O L}\left(1+C_{r} \gamma_{\lambda \theta}\right)(A)\left(r_{m}\right)
$$

where $A$ is the total ligament cross sectional area and $r_{m}$ is an effective moment arm, which, for a thin cylinder wall, is the mean radilis. Q represents the supporting effect of the aluminum oxide.

The effective cross sectional area of the ligaments is again presumed to be reduced by ligament slippage associated with extensional strain, $\epsilon_{x}$, parallel to the ligaments, but this slippage is now impeded by the clamping effect of normal stress, $\sigma_{y}$. Equation 4 may be rewritten:

$$
A=A_{1}\left(1-k \epsilon_{x}\left(\frac{\sigma_{y 1}-\sigma_{y}}{\sigma_{y 1}}\right)\right]
$$

where $\sigma_{y l}$ is a "locking stress" which prohibits ligament slippage. If $\sigma_{y}$ is equal to $\sigma y l$, there is no slippage and if $\sigma_{y}$ is zero (as in the case with uniaxial tensile loading) there is no clamping effect to. impede slippage. The torque may now be rewritten: 


$$
T=\tau_{o} \rho r_{n I} A_{I}\left[1-k \epsilon_{x:}\left(\frac{\sigma_{y I}-\sigma_{y}}{\sigma_{y l}}\right)\right]\left(1+c_{Y} \gamma_{a \theta}\right)
$$

At any given instant the torque may also be stated in terms of the cross sectional area of the cylindrical specimen which, for the powder aluminum remains $A_{I}$, and the shear stress, ${ }^{n} \theta$ which remains a simple function of this area:

$$
T=\tau_{12} A_{C} I_{m}
$$

or:

$$
\tau_{n \theta}\left(A_{O} I_{a l}\right)=\sigma \tau_{o r} I_{u r} A_{0}\left(1-k \epsilon_{x}\left(\frac{\sigma_{y I}-\sigma_{y}}{\sigma_{y 1}}\right)\right)\left(1+c_{x} \gamma_{n \theta}\right)
$$

which reduces to:

$$
\tau_{n \theta}=Q \tau_{\sigma x}\left[1-k \varepsilon_{x}\left(\frac{\sigma_{y-1}-\sigma_{y}}{\sigma_{y 1}}\right)\right]\left(1+c_{x} \gamma_{n \theta}\right)
$$

Biaxial loading experiments were performed to determine the material parameters in equation 13. The equations then were tested by fitting to data in the post-yield region from the three specimens in figure 2. Values for $\tau_{\text {or }}$ and $c_{r}$ are values for 1100 aluminum. The constant, $Q$, is obtained from simple shear tests of 1100 aluminum and powder alumirum. These values were determined to be: $\tau_{\text {or }}=6.5 \mathrm{MPa}, c_{\mathrm{r}}=0.7$ and $\mathrm{Q}=1.75$. The values for $\tau_{\text {or }}$ and $c_{r}$ are the same for all specimens because the yield stress did not vary greatly on the portion of the yield surface in strain space which contained the strain ratios experienced by the powder aluminum specimens tested in tension and torsion and because the strain hardening coefficient is relatively constant for the strain ratios experienced by the powder aluminum [18]. Q is the same for all specimens because the yield stress is the same for all specimens. Values for $k$ and $\sigma_{y l}$ were found numerically using nonlinear least squares reduction $[19]$.

Values for $k$ and $\sigma_{y l}$ were found three ways. Data for each specimen were used alone to find the constants for that specimen. Data for all three were used together. Finally, data from three additional specimens tested to lower levels of maximum shear and extensional strain [1] were added to the total amount of data. All values of $k$ and $a y l$ are $l i s t e d$ in
rable $?$.

If the material variation from billet to billet is small enough, then $k$ and $\sigma_{y l}$ should be nearly constant for specimens taken from billets 
of the same material extruded under the same conditions and tested at the same strain rate. Also, the values obtained by the least-squares reduction should be reasonable; $k$ should be positive and $\sigma_{y l}$ should be compressive and should have magnitude greater than or equal to the largest clamping stress, $\sigma_{y}$, experienced in the test specimens. $\sigma_{y l}$ should also not be unreasonably large, but should be the same order of magnitude as the maximum clamping stress experienced by the test specimens. As discussed previously, the clamping stress is greatest in a specimen loaded in pure torsion. In these experiments, a value of -4.0 MPa was obtained in a specimen subjected to an angle of twist of $95^{\circ}$ in the simple torsion experiment.

Figures 7-9 show plots of the experimental results for $\tau_{n}$ for three biaxial test specimens compared with $\tau_{n \theta}$ computed using equation 13 for the different values of constants $k$ and $\sigma_{y l}$. The equation fits the data very well when the data to determine $k$ and $\sigma_{y l}$ is taken only from the specimen being fitted. This is true for all specimens and indicates that on an individual basis, the proposed model does provide a reasonable template to describe the experimental data. For all cases, the values of $k$ and $\sigma_{y l}$ are also reasonable. The equation $f i t$ is poorest for the simple torsion specimen, Figure 12 , when $k$ and $\sigma_{y l}$ are determined from the larger pools of data. This is nearly a limiting case for tensiontorsion testing and for application of equation 13. As noted earlier, the clamping stress, $\sigma_{y l}$, is the highest for this case. There is also no axial extensional strain in this test and $\epsilon_{x}$ is a function of only the shear. These conditions may help to produce the different values for $k$ and $\sigma_{y l}$ for this specimen. It must be noted that there is a billet to billet variation in material and possibility of variations within a billet for the powder aluminum, due to several operations performed by hand during fabrication [1]. This could also be responsible for the variations in the constants. Specimens for figures 12 and 13 were obtained from a single billet; that for figure 14 was from a different billet. The three additional test specimens were from a third billet.

\section{Discussion}

The principal objective of this research was to determine methods for improving the extrusion of powder metal tubular products. Shear failures of the material were a comon problem when using a conical extrusion die.

Visioplastic analysis[20] of the extrusion showed a region where tensile radial strains, normal to the extrusion direction, were experienced near the entry region of the die. The presence of these strains demonstrated the absence of clamping of the ligaments in this region. The resulting lower shear strength of the material encouraged the early failure. 
The extruded product was improved by redesigning the die using a cosine shaped profile. Visioplastic analysis showed that this die produced compressive strains in the radial direction throughout the extrusion region, for an improved product[21].

Acknow ledgement

The information contained in this paper was developed during the course of work under Contract No. DE-ACO9-895SR18035 with the U.S. Department of Energy. The authors are grareful for this support.

\section{References}

1. Woods, T.O., and Berghaus, D.G., "The Biaxial Loading Response of Powder Aluminum at Elevated Temperature", Experimental Mechanics, $34(3), \mathrm{pp} .249-295$, (1994)

2. Friedman, G., "Properties of Extruded Metal Powders", International Journal of Powder metallurgy and Powder Technology, 16(1), 1980, pp. $29-35,(1980)$

3. Paris, H.G., Mullins,J.W., and Sanders, T.H., Jr., "The Effect of Solidification Microstructure on the strength, Ductility, and Toughness of Dispersion-Hardened Al P/M Alloys", High Strength Powder Aluminum Alloys, Ed. M.J. Koczak and G.J. Hildeman, The Metallurgy Society of AIME, Warrendale, PA, pp. 277-295, (1982)

4. Grinder, O., Stahliberg, U., and Savage, S., "Hot Extrusion of Encapsulated Powder", Proceedings of International Conference: Sintering ' 87 , Tokyo (1987)

5. Park, S.C. and Park, W.K., "Properties of Extruded Aluminum-Iron P/M Materials', International Journal of Powder metallurgy and powder Technology, 14(4), pp. 305-321, (1978)

6. Bay, B. and Hansen, "The Influence of Small Particles and Grain Boundaries on the Deformation Structure of Aluminum", Deformation of Miilti-Phase and Particle containing Materials: Proceedings of the 4 th Riso International Symposium on Metallurgy and Materials Science, Roskilde, Denmark, pp. 145-152, (1983)

7. Kim, Y.W. and Griffith, W.M., Annealing Behavior and Tensile Properties of Elevated Temperature PM Aluminum Alloys", Rapidly Solidified Powder Aluminum Alloys, ASTM STP 890, Ed. M.E. Fine and E.A. Starke, Jx., ASTH, Philaueiphia, PA, pp. 485-511, (1986) 
8. Ivanov, V.E., Zelenskii, V.F., Savchenko, V.I., Faifer, S.I., and Zhandov, S.M., "Internal Friction in Magnesium Cermet". Internal Friction in Metals and Alloys", Ed. V.S. Postnikov, F.N. Tavadze and L.K. Gordienko, Consultants Bureau, New York, pp. 176-179, (1967)

9. Ivanov, V.E., Zelenskii, V.F., Faifer, S.I., Savchenko, V.I., ana Maksimenko, V.I., "Internal Friction in Beryllium Cermet", Internal Friction in Metals and Alloys", Ed. V.S. Postnikov, F.N. Tavadze, and L. K. Gordienko, Consultants Bureau, New York, pp. 180-183, (1967)

10. Karlsson, B. and Bertilsson, ":Mechanical Properties of Sintered steels", Scandinavian Journal of Metallurgy, 11, pp. 267-275, (1982)

11. Sater, J.M., Sanders, T.H. Jr., and Garrett, R.K. Ir., "Characterization of Rapidly Solidified Materials" Rapidiy Solidified Powder Aluminum Alloys, ASTM STP 890, Ed. M.E.Fine and E.A. Starke Jr., ASTM, Philadelphia, pp 83-117, (1986)

12. Bretheau, R. and Caldemaison, D., "Study of Inclusion-Matrix Interaction by means of Local strain Measurements", Deformation of Multi-Phase and Particle Containing Materials: Proceedings of the 4 th Riso International Symposium on Metallurgy and Materials Science, Roskilde, Denmark, p. 173-178, (1983)

13. Hamiuddin, M. "Prediction of Mechanical Properties of porous Materials and Cermets - A critical Analysis". Powder Metallurgy International, 19(6), pp. 25-27, (1987)

14. Navarra, E. and Bengston, B. "Fracture Toughness of P/M Steels", International Journal of Powder Metallurgy and Powder Technology, $20(1)$, pp. 33-43, (1984)

15. Underwood, E.E., Quantitative Stereology, Addison-Wesley Publishing Co., Reading, MA, (1970)

16. DeHoff, D.T. and Aigeltinger, E.H., "Experimental Quantitative Microscopy with Special Applications to Sintering", Perspectives in Powder Metallurgy, Vol. 5: Advanced Experimental Techniques in Powder Metallurgy, Ed. J. S. Hirschhorn and Roll, K.H., Plenum Press, New York, pp.81-137, (1970)

17. Dally, J.W. and Riley, W.P., Experimental Stress Analysis, 2nd Ed., McGraw-Hi1l, New York, 1966, pp. 18-20, (1978)

18. Woods, T.O., "An Investigation of the Mechanical Properties and Microscopic Structure of Extruded Powder Aluminum Subjected to Biaxial Loadings at Elevated Temperature", Doctoral Dissertation. Georgia Institute of Technology, Atlanta, GA, (1991)

19. Oraper, N.R. and Smith, H., Applied Regression Analysis, John Wiley and Sons. New York, 1966, pp. 263-284, (1966) 
20. Berghaus, D.G., Primas, R.J., and Peacock, H.B., "strain Analysis for Extrusion of Powder Metals", Experimental Mechanics, 28(9), pp.232$237,(1988)$

21. Berghaus, D.G., McCue, J.M., and Peacock, H.B., "Comparison of Extrusion strains produced by cosine and Conical Dies", Journal of Materials Engineering and Performance, 4(1), pp. 25-31, (1995) 


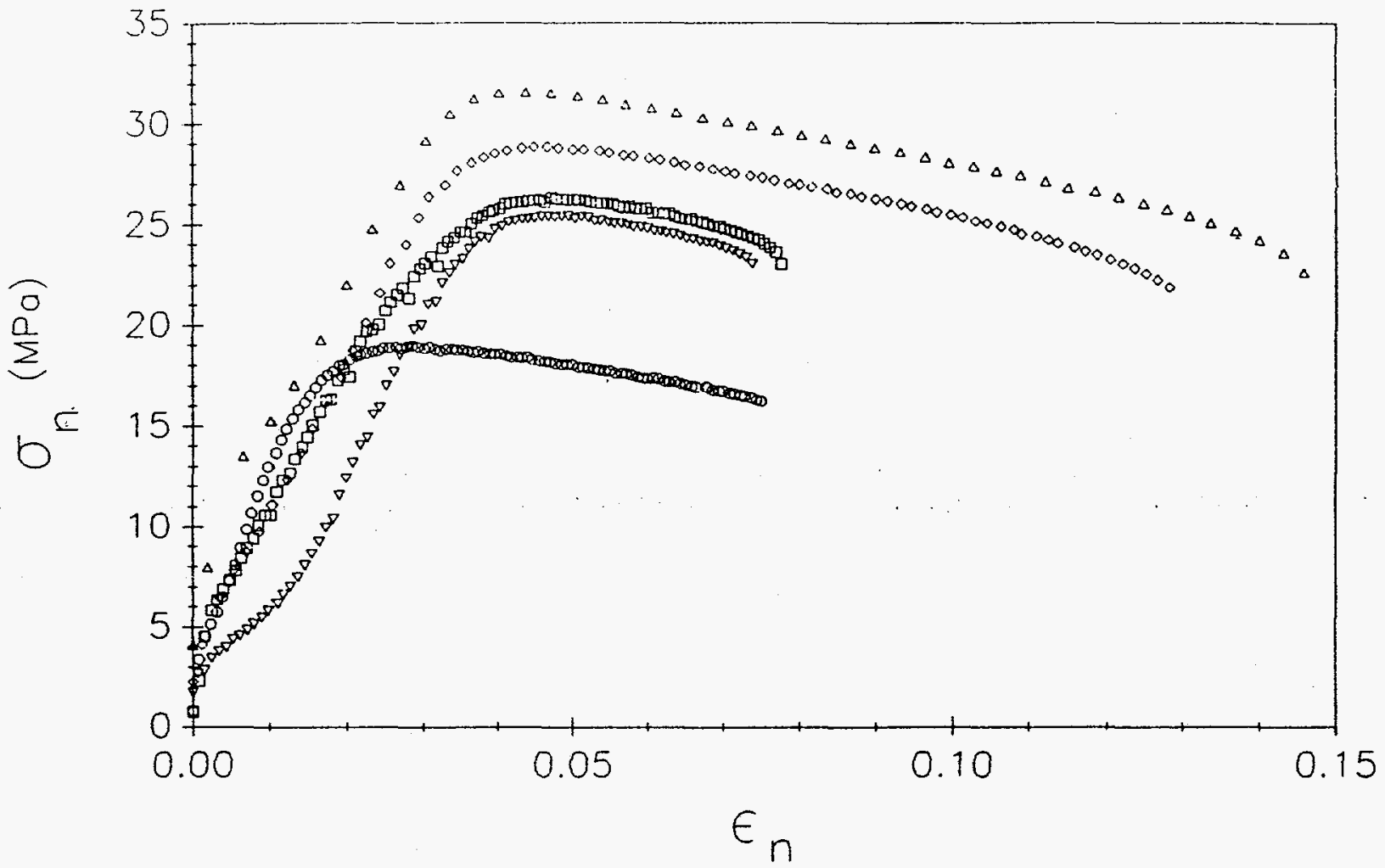

Ire 1. Normal stress vs extensional strain for powder aluminum specimens tested in simple tension at $427^{\circ} \mathrm{C}$. 


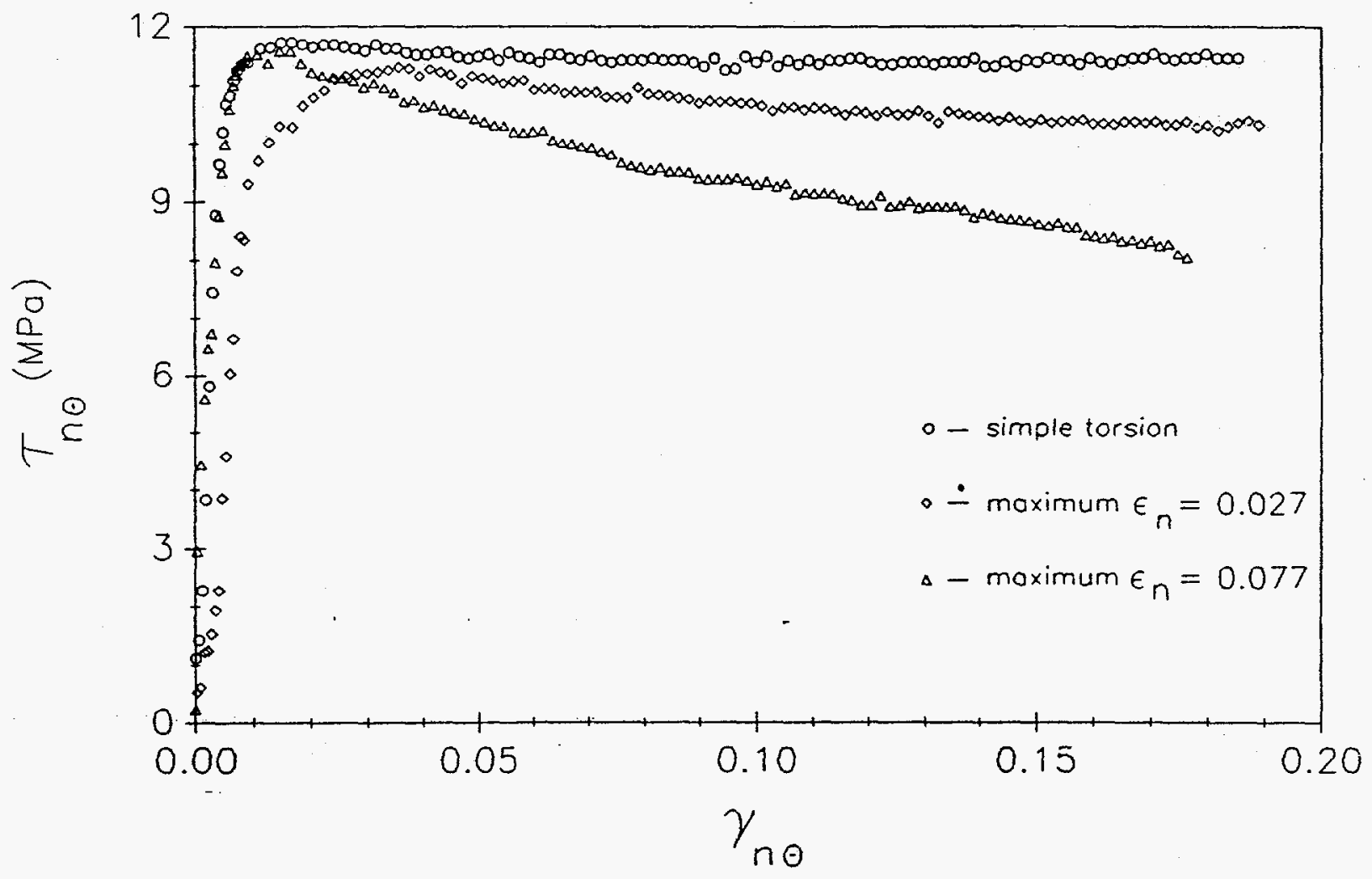

Figure 2. Shear stress vs shear strain for three yowder aluminum specirnens loaded biaxially in tension and torsion or loaded in simple torsion to a final angle of twist of $95^{\circ}$ at $427^{\circ} \mathrm{C}$. 


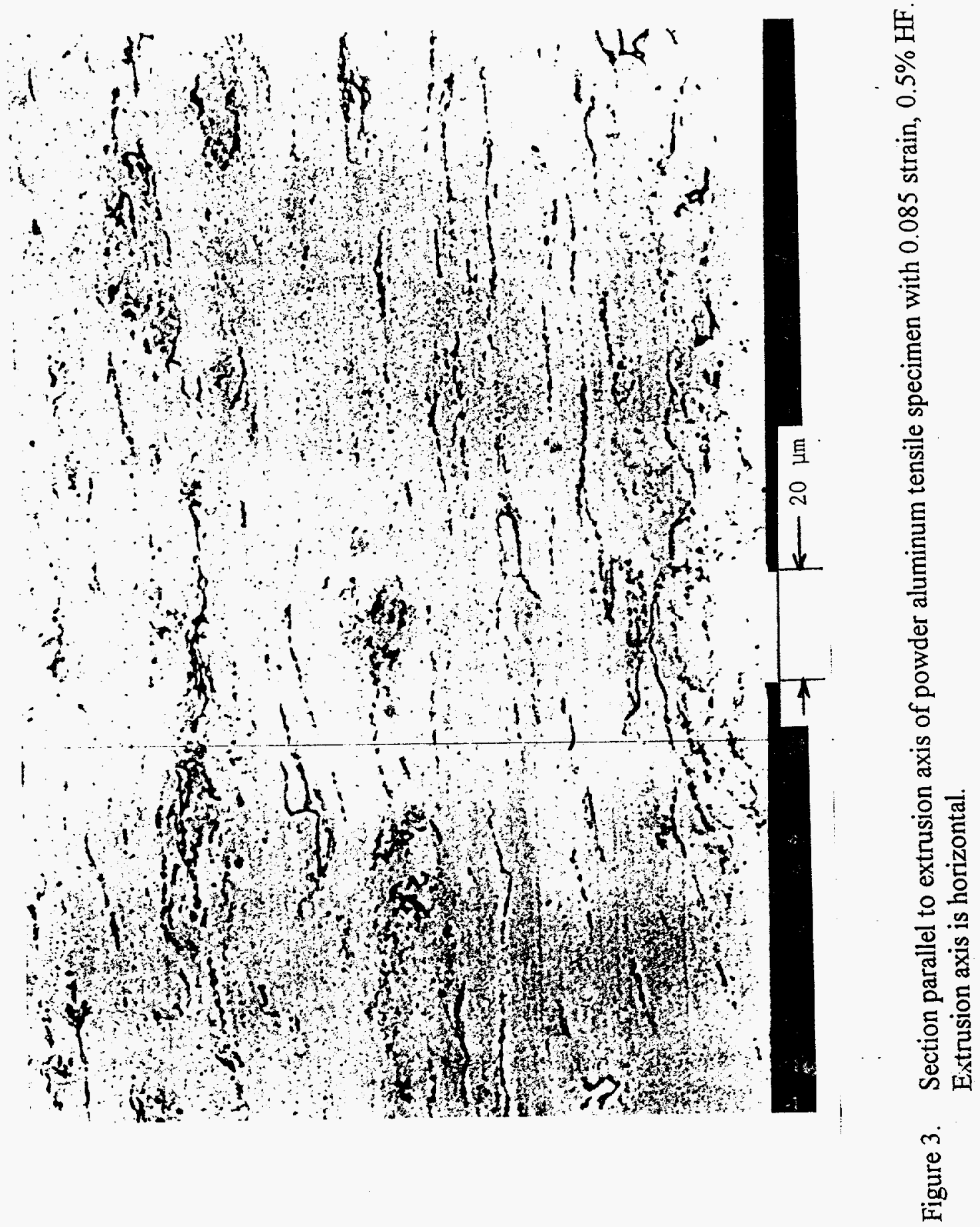




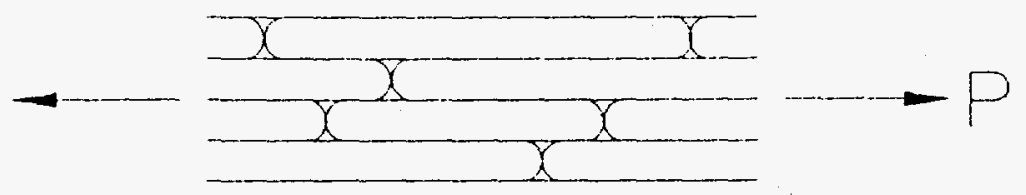

gure 4a. Aluminum ligament behavior under load before slip.

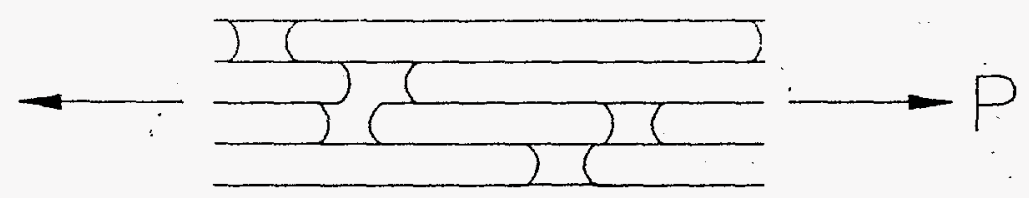

jure 4b. Aluminum ligament behavior under load after slip. 

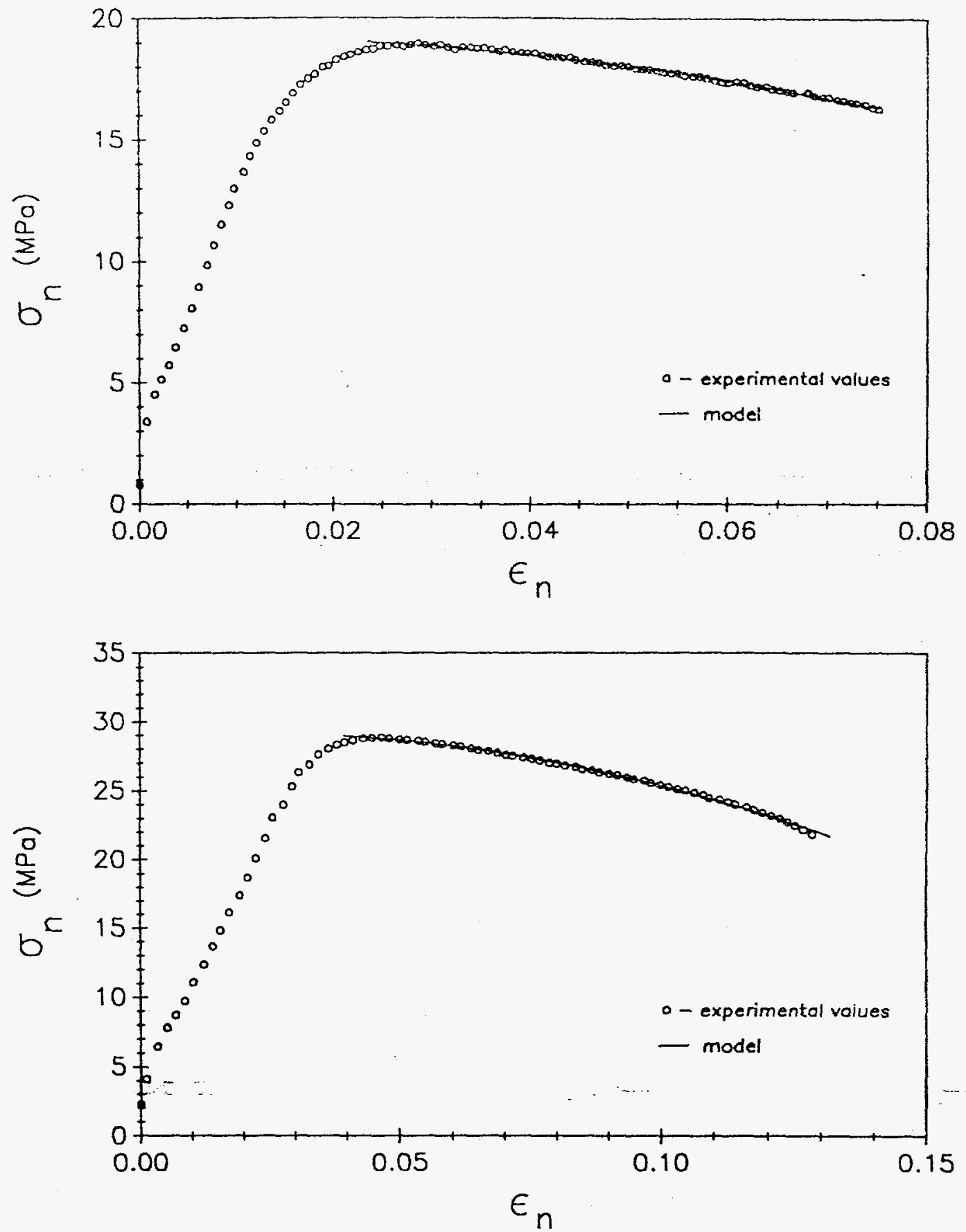

igure 5. Normal stress vs extensional strain for powder aluminum specimen HT1 (above) and NT3 (below) in simple tension at $427^{\circ} \mathrm{C}$. Graph shows experimental data and fit from equation 6. 


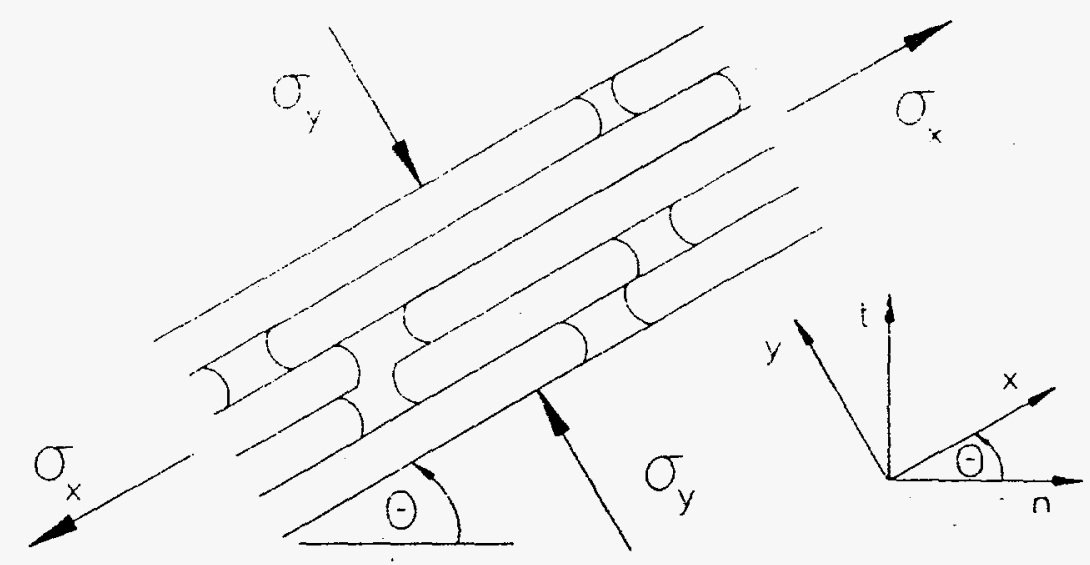

z̧ure 6. Normal stresses acting on an enlarged region in a powder aluminum specimen loaded in tension and torsion. The extrusion axis (and the axis of tension and torsion) is the $n$-axis. The $x$-axis is aligned with the aluminum ligaments. Shear stresses are not shown. 


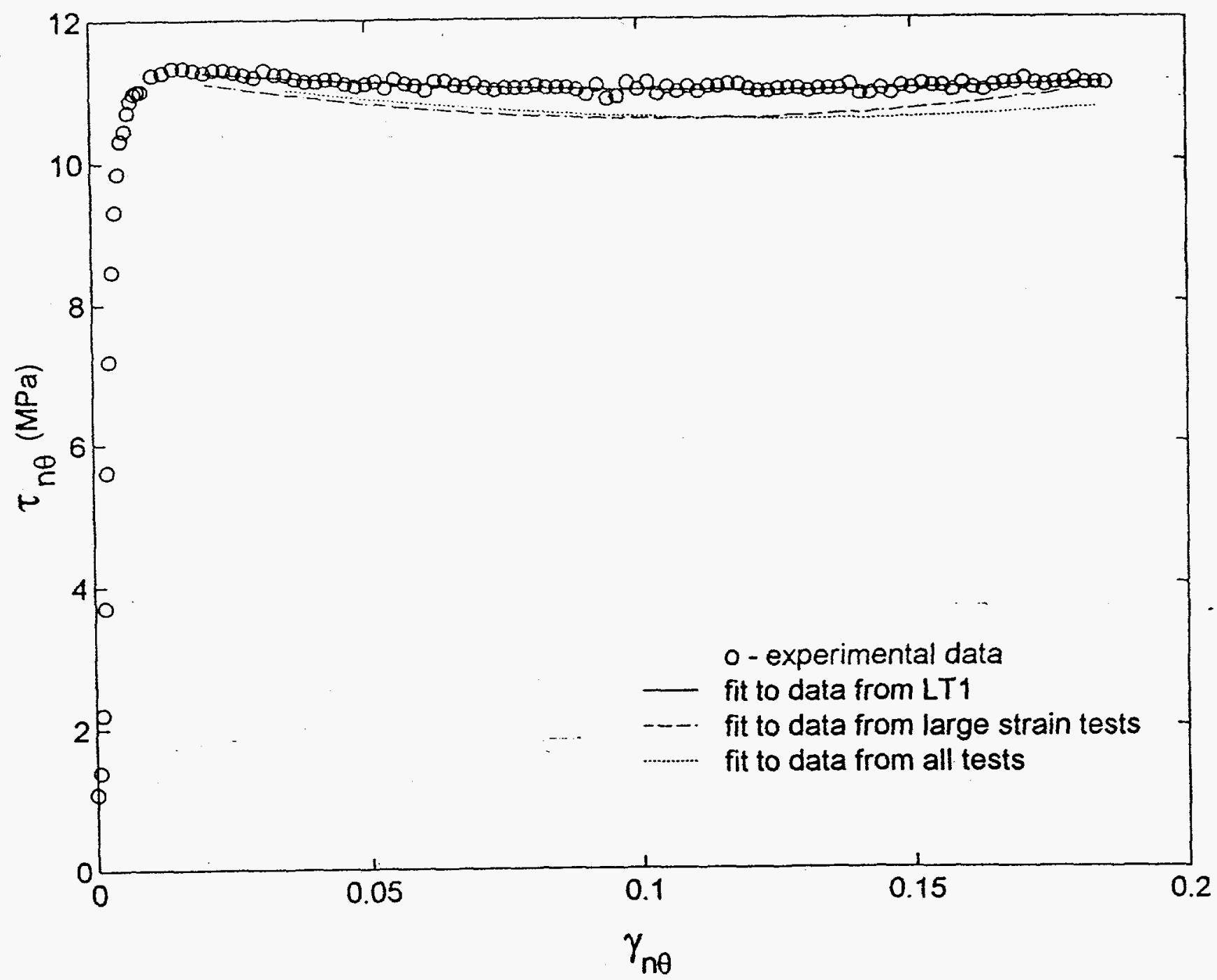

igure 7. Shear stress vs shear strain for extruded powder aluminum specimen LTl tested in pure torsion at $425^{\circ} \mathrm{C}$. Graph shows experimental data and fit from equation 14 using data from specimen LTl alone, from large strain tests, and from all tests. 


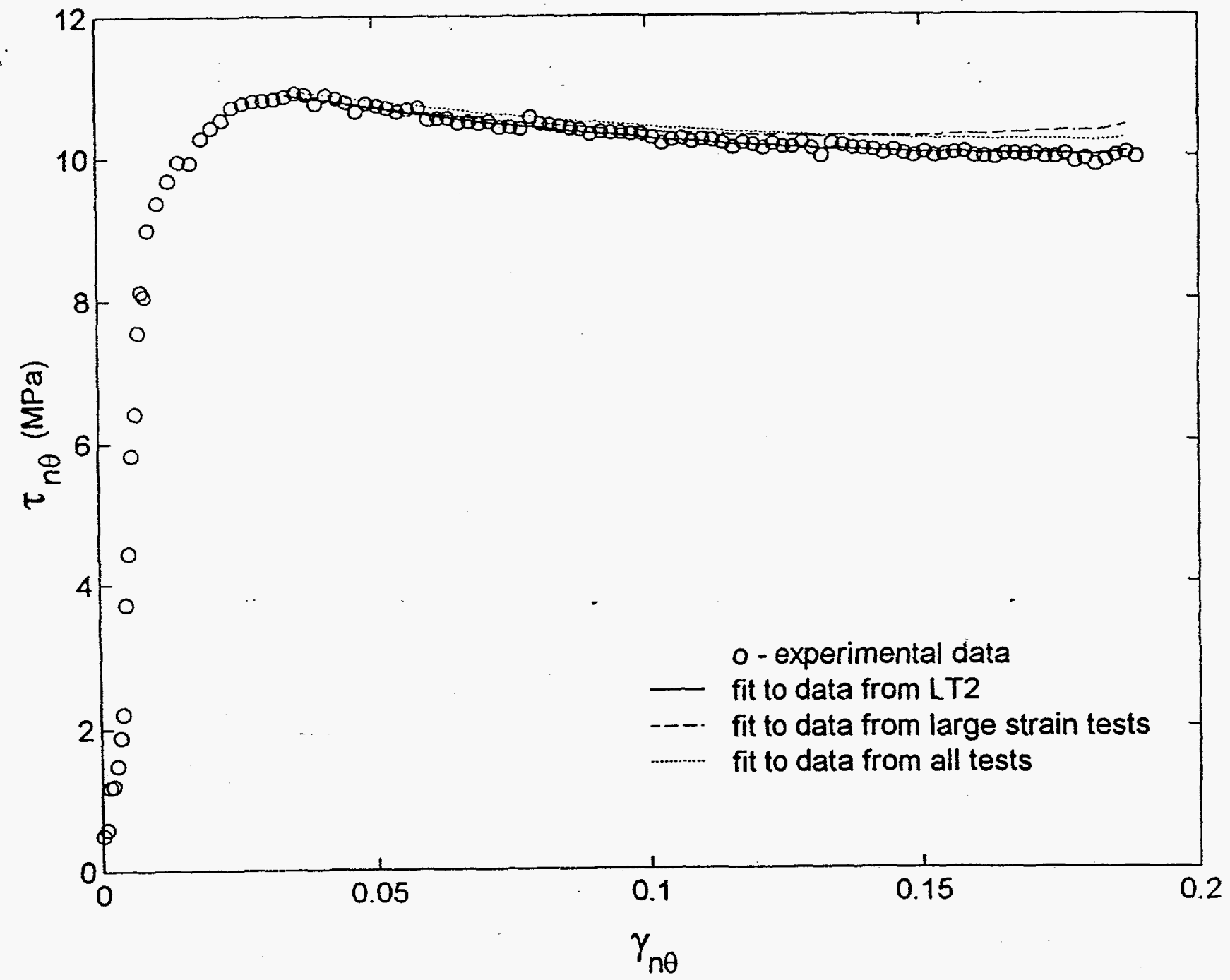

Figure 8. Shear stress vs shear strain for extruded powder aluminum specimen LT2 tested biaxially at $425^{\circ} \mathrm{C}$. Maximum axial strain is 0.027 . Graph shows experimental data and fit from equation 14 using data from specimen LT2 alone, from large strain tests, and from all tests. 


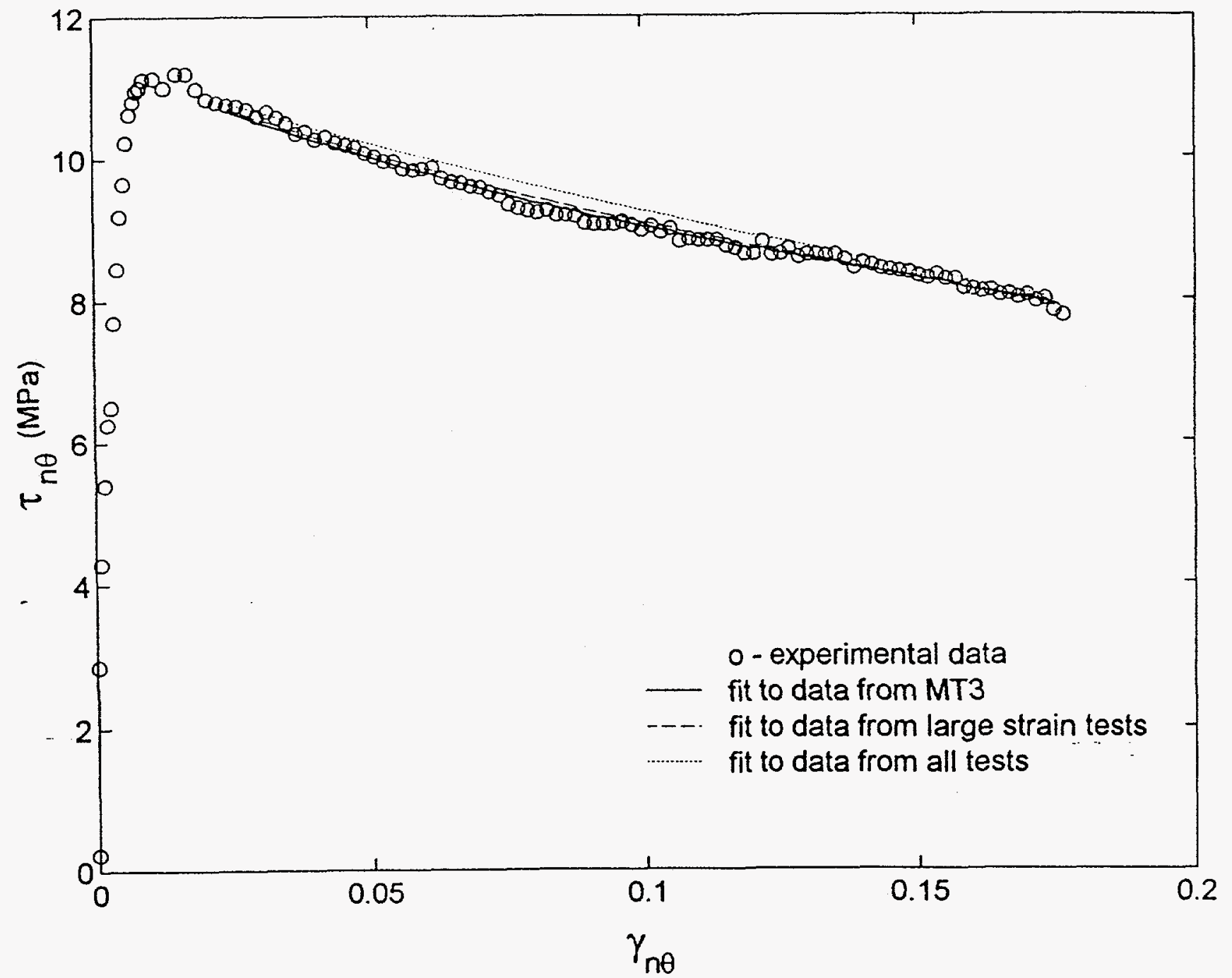

Figure 9. Shear stress vs shear strain for extruded powder aluminum specimen MT3 tested biaxially at $425^{\circ} \mathrm{C}$. Maximum axial strain is 0.077 . Graph shows experimental data and fit from equation 14 using data from specimen MT3 alone, from large strain tests, and from all tests. 
Table 1.

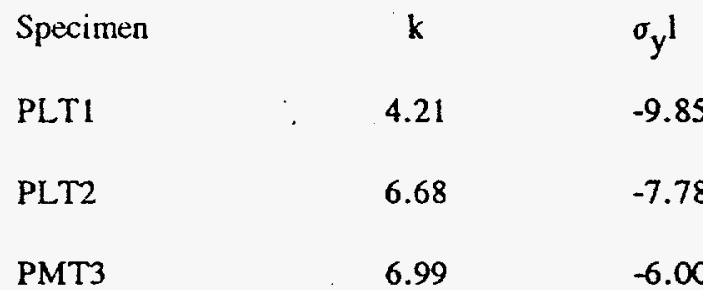

Combined Value for

PLT1, PLT2, PMT3

6.64

$-6.59$

Combined Value

Six Specimens

5.90

$-8.19$ 